\title{
Spatial variation of water quality parameters in a mangrove estuary
}

\author{
K. Fatema $\cdot$ W. O. Wan Maznah $\cdot$ M. M. Isa
}

Received: 1 August 2012/Revised: 11 March 2014/Accepted: 28 April 2014/Published online: 27 May 2014

(C) Islamic Azad University (IAU) 2014

\begin{abstract}
Spatial variations of the water quality parameters of the Merbok estuary were interpreted by multivariate statistical techniques, such as cluster analysis (CA), principal component analysis (PCA), and factor analysis (FA). Data from January to December 2011 were collected to monitor 13 parameters at six sampling stations along the river stretch (two stations at each river section: upstream, midstream, and downstream). Cluster analysis results revealed two different groups between the sampling stations, reflecting different physicochemical properties and pollution levels in the study area. Factor analysis was used for the parameters of the surface and bottom water quality, yielding four factors that were responsible for 72.93 and $68.90 \%$ of the total variance of data sets. PCA also found conductivity, salinity, dissolved oxygen, chlorophyll $a$, and $\mathrm{NO}_{3}{ }^{-}$to be the most important parameters contributing to the fluctuations of surface water and bottom water quality in the Merbok estuary. This study presents the usefulness of multivariate statistical techniques for assessing water quality data sets and for understanding spatial variations in water quality parameters to effectively manage water quality in estuaries.
\end{abstract}

Keywords Cluster analysis - Factor analysis . Merbok estuary $\cdot$ Physicochemical parameters

K. Fatema · W. O. Wan Maznah ( $)$ · M. M. Isa

School of Biological Sciences, Universiti Sains Malaysia,

11800 Penang, Malaysia

e-mail:wmaznah@usm.my

K. Fatema

Department of Fisheries, University of Dhaka,

Dhaka 1000, Bangladesh

W. O. Wan Maznah · M. M. Isa

Center for Marine and Coastal Studies (CEMACS),

Universiti Sains Malaysia, 11800 Penang, Malaysia

\section{Introduction}

The estuaries and coastal areas of Malaysia are exposed to massive anthropogenic activities. As a result, most of the estuaries have become polluted. Forty-two tributaries in Peninsular Malaysia have been classified as highly polluted (Aiken et al. 1982), and 13 tributaries along with 36 rivers are moderately polluted because of anthropogenic activities, such as industry, construction, and agriculture (DOE 1999). Approximately $60 \%$ of the water of major rivers is used for domestic, agricultural, and industrial purposes (DID 2001). Sewage disposal, discharges from small- and medium-sized industries without proper effluent treatment systems, land clearing, and earthwork are the major factors responsible for river pollution in Malaysia (Rosnani 2000; Juahir et al. 2011).

Water quality is influenced by both natural processes (such as precipitation rate, weathering, and soil erosion) and anthropogenic activities (including urban development, industrial and agricultural activities, and human exploitation of water resources) (Pejman et al. 2009; Yang et al. 2012). These activities often cause the degradation of water quality, physical habitat, and the biological integrity of lotic systems (Varol and Sen 2009).The overexploitation of water resources in catchment areas is responsible for much of pollution load (Singh et al. 2005). The quality of a river or a stream at any point represents basin lithology, atmospheric input, climatic conditions, and anthropogenic input. Rivers and streams assimilate or carry off municipal and industrial wastewater and runoff from agricultural land. Municipal and industrial wastewater discharges continuously, whereas surface runoff input eventually, depending on the climatic condition of the basin (Pradhan et al. 2009; Hu et al. 2012). Water chemistry in rivers and streams depends on spatial and temporal variation and shows high heterogeneity at different spatial scales. Local environmental conditions (e.g., light intensity, water velocity, 
temperature, and discharge) are determinant factors for spatial heterogeneity within the stream. Increasing population growth expands economic activity, and rapid industrialization increases water demand. In addition, rapid urbanization is altering the patterns of consumption, causing the severe misuse of water resources. Rivers, streams, and their tributaries passing through cities receive many contaminants released from industrial, domestic/sewage, and agricultural effluents and thereby accelerate the degradation of fresh water ecosystem mainly by eutrophication (Qadir et al. 2008; Zhang et al. 2011; Mustapha and Aris 2012).

Spatial and temporal variations in surface water quality have been measured through multivariate statistical techniques (Alkarkhi et al. 2009; Bu et al. 2010; Huang et al. 2011; Juahir et al. 2011; Varol et al. 2012; Wang et al. 2012; Mustapha et al. 2013). The Merbok River, a mangrove estuary in wet tropical Peninsular Malaysia, is heavily impacted by human activities such as agriculture, aquaculture, pond culture, cage culture, artisanal fisheries, and land development. Merbok River is an immense source of fisheries. Many locals depend on fishing on this estuary for their livelihood. The estuary is used for breeding and spawning and is a nursing ground for resident and migratory fish species. The estuary is also a recreational place for locals and tourists. Thus, many people depend on the water resources of this estuary. However, few studies have examined the water quality of rivers and streams in Malaysia especially in Merbok. Therefore, the water quality of this estuary should be determined to assess its environmental conditions and thus contribute to improving the management of the estuary.

There are many ways to monitor water conditions (EPA 2002). Generally, water quality monitoring focuses on the physical and chemical parameters and a few key biological parameters. Examination of the extensive literature on this issue indicates that still there is no consensus as to the class or complex of parameters that characterize water quality status of estuaries. Some authors represent water quality status by dissolved oxygen, biochemical oxygen demand, chemical oxygen demand, suspended solids, $\mathrm{pH}$, conductivity, salinity, temperature, nitrogen in the form of ammonia, turbidity, dissolved solids, total solids, nitrates, chloride, and phosphates (Iscen et al. 2008; Mustapha and Abdu 2012). Others (Meera and Nandan 2010) have examined water quality status combining some of these physicochemical parameters with the measurement of the chlorophyll pigments' contents. To have insights into the phytoplankton abundance and biomass in our study, we focused on chlorophyll $a$, as previously carried out elsewhere (Meera and Nandan 2010). Present study measured chlorophyll $a$ to assess trophic status of the estuary as it is a valuable indicator of phytoplankton abundance and biomass. This pigment alone is believed to be a valuable index of the productivity and trophic condition of estuaries (Boyer et al. 2009). Its concentrations are an indicator of phytoplankton abundance and biomass in estuarine waters and thus an effective measure of trophic status (ANZECC/ARMCANZ 2000). For Rossouw (2003), chlorophyll $a$ concentrations can be considered the most important biological response variable for nutrient-related problems. From a mathematical approach, evidence has been produced, which demonstrated that chlorophyll $a$ is the best proxy of phytoplankton biomass (Huot et al. 2007). The amounts of chlorophyll $a$ are potential indicators of photosynthetic rate and are a commonly used measure of water quality (Nichol et al. 2013). This study was set to examine water quality status in Merbok estuary based on physicochemical parameters and chlorophyll $a$. Different multivariate statistical techniques, such as cluster analysis (CA), principal component analysis (PCA), and factor analysis (FA), have been widely applied to interpret and analyze complex environmental data matrices to better understand the water quality and ecological information of the studied area. This research intends to apply PCA, FA, and CA techniques: to explore the extent of similarity and dissimilarity among the sampling stations and to extract critical parameters that are most relevant to assess spatial variations in water quality in Merbok estuary.

\section{Materials and methods}

\section{Study area}

The Merbok River $\left(5^{\circ} 30^{\prime} \mathrm{N}, 100^{\circ} 25^{\prime} \mathrm{E}\right)$ is the mouth of major rivers in southern Kedah (Fig. 1). The river flows into the Straits of Malacca after passing through an alluvium plain of rice fields on its freshwater course and mangroves on its estuarine course. The river is about $35 \mathrm{~km}$ long and 3 to $15 \mathrm{~m}$ deep and has a few $20 \mathrm{~m}$ deep holes where tributaries join the Merbok (Kjerfve 1979; Ong et al. 1991). Seawater intrudes up to about $30 \mathrm{~km}$, although the river is tidal for almost its entire length. The tidal range in the nearest coastal area is from 0 to $2.9 \mathrm{~m}$. The freshwater part of the main river is only a few meter wide. Freshwater flows into the estuary through numerous tributaries and ground runoff (sheet flow) during heavy rainfall. The estuary is connected to the Muda River in the south via a channel. Muda River is a major river with an average water discharge of about $100 \mathrm{~m}^{3} \mathrm{sec}^{-1}$ (DDI 1974). The catchment area of Merbok River consists of alluvial deposits overlying an extensive span of ferruginous shale and mudstone, with a few scattered outcrops of granite and ferruginous sandstone/quartzite measuring $550 \mathrm{~km}^{2}$. The water-covered area of the estuary measures $20 \mathrm{~km}^{2}$ at low water. Mangrove vegetation in the intertidal zone of Merbok River measures $50 \mathrm{~km}^{2}$.

In this study, six sampling stations were chosen to reflect the human activities, such as agriculture, aquaculture, and 
Fig. 1 Map showing the sampling stations locations of Merbok estuary during January to December 2011

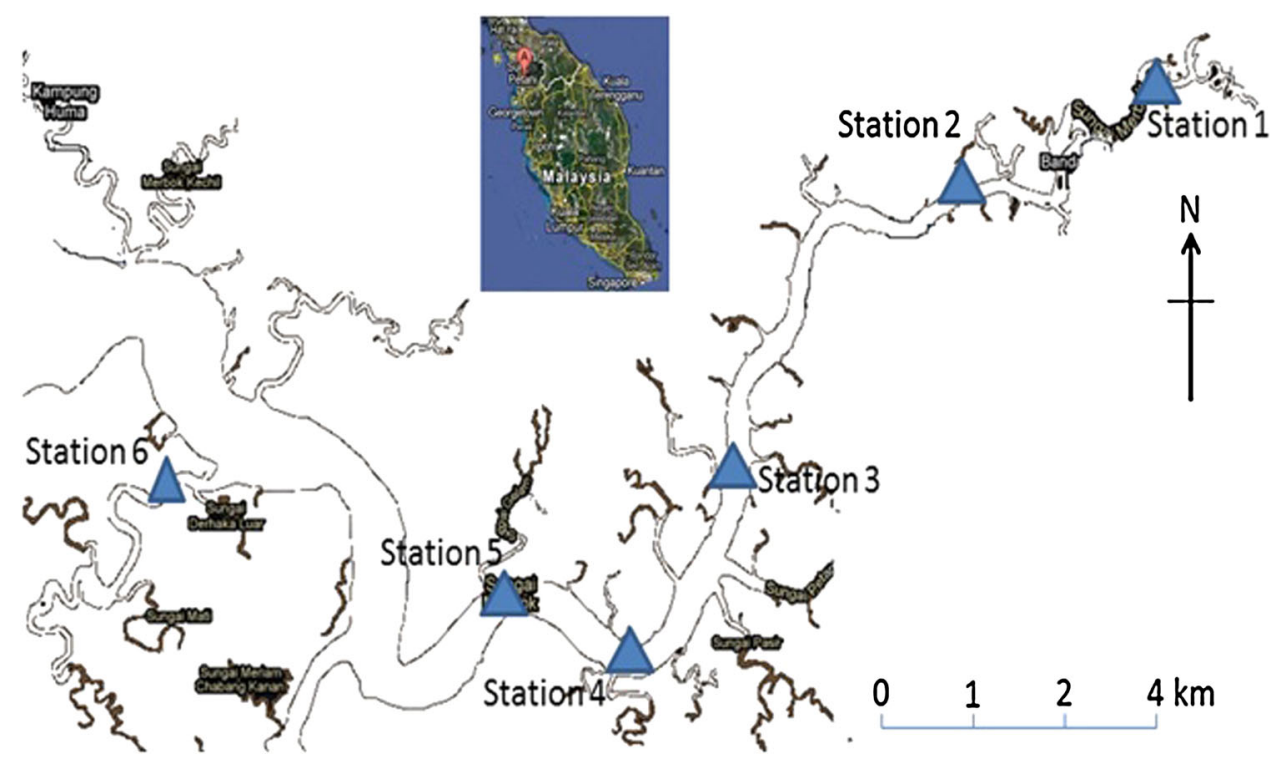

land development in the vicinity. Stations 1 (Lalang River, $05^{\circ} 41^{\prime} 56.63^{\prime \prime} \mathrm{N} 100^{\circ} 30^{\prime} 16.94^{\prime \prime} \mathrm{E}$ ) and 2 (Semeling River, $\left.05^{\circ} 41^{\prime} 13.66^{\prime \prime} \mathrm{N} 100^{\circ} 28^{\prime} 32.19^{\prime \prime} \mathrm{E}\right)$ were located upstream. Stations 3 (Jagung River, $05^{\circ} 39^{\prime} 27.33^{\prime \prime} \mathrm{N} 100^{\circ} 26^{\prime} 58.00^{\prime \prime} \mathrm{E}$ ) and 4 (Teluk Wang, $05^{\circ} 38^{\prime} 2.87^{\prime \prime} \mathrm{N} 100^{\circ} 25^{\prime} 57.67^{\prime \prime} \mathrm{E}$ ) were located in the midstream, where aquaculture activities were prevalent. Stations 5 (Gelam River, $05^{\circ} 38^{\prime} 37.68^{\prime \prime} \mathrm{N}$ $100^{\circ} 25^{\prime} 4.01^{\prime \prime} \mathrm{E}$ ) and 6 (Derhaka River, 05 $39^{\prime} 26.27^{\prime \prime} \mathrm{N}$ $100^{\circ} 23^{\prime} 3.27^{\prime \prime} \mathrm{E}$ ) were located downstream, where aquaculture activities and artisanal fishing were similarly prevalent.

Sample collection and analytical methods

Water samples were collected from six sampling stations at monthly interval between January and December 2011. Bottom samples were collected from 2.17 to $3.83 \mathrm{~m}$ depths of different sampling stations by using Alpha water sampler (Wildco, Model no. 1120-C 40, USA). It consists of a cylinder, approximately $12 \mathrm{~cm}$ in diameter and $36 \mathrm{~cm}$ in length. Each end of the cylinder was covered with spring-loaded flaps, which can be held in the fully open position by latches. The latches were released by applying a small amount of pressure to a lever. To accomplish this, a weight (called a "messenger") was dropped down the lowering rope, the latch was tripped, and the ends of the cylinder close. When the sampler was in use, the end flaps were latched into the open position. As the sampler was lowered to the required depth with the lowering rope, water was passed through the open ends so that, at any depth, the water in the sampler was the water from that depth. When the desired depth was reached, the messenger weight was dropped down the rope, the latch was tripped, and the end flaps close. The sampler is brought to the surface and its contents/water was transferred to a sample bottle. Surface and bottom water was collected from each station (three replicates) in acid-washed polythene bottles (1.5 l) for laboratory analysis. All the samples were kept in the dark and cool temperature $\left(4{ }^{\circ} \mathrm{C}\right)$ in the cool box before transporting to the laboratory. Temperature, salinity, and electrical conductivity were measured at each sampling station with Hydrolab Surveyor 3 Data Logger (Model no\# SVR3-DL, USA). Dissolved oxygen (DO) was recorded by a DO meter (YSI Model 52). The $\mathrm{pH}$ was measured by a $\mathrm{pH}$ meter (eco $\mathrm{Testr}^{\mathrm{TM}}, \mathrm{pH}=2$ ). Water transparency was observed with a Secchi disk $20 \mathrm{~cm}$ in diameters (Wetzel and Likens 2000). The samples collected from the field were kept in a refrigerator below $4{ }^{\circ} \mathrm{C}$ to reduce the activity and metabolism of the organisms in the water (Adams 1991).

Nitrite $\left(\mathrm{NO}_{2}^{-}\right)$and Nitrate $\left(\mathrm{NO}_{3}{ }^{-}\right)$

Nitrite $\left(\mathrm{NO}_{2}^{-}\right)$concentration was measured using calorimetric method (Strickland and Parsons 1972). In this method, water samples were treated with sulfanilamide in acid solution with diazonium compounds, which reacted with $\mathrm{N}$-(1-naphtyl)-ethyleneamine dihydrochloride to form an azo dye. Then, absorbance was measured by a spectrophotometer (HITACHI, Model no. U-1900, Japan) at $543 \mathrm{~nm}$, whereas nitrate $\left(\mathrm{NO}_{3}{ }^{-}\right)$was determined through cadmium reduction. In this method, the reduction changes nitrate $\left(\mathrm{NO}_{3}{ }^{-}\right)$to nitrite $\left(\mathrm{NO}_{2}{ }^{-}\right)$by passing the sample water through a copper-cadmium reduction column. Then, nitrate reduced to nitrite was determined by the calorimetric method.

Phosphate $\left(\mathrm{PO}_{4}{ }^{3-}\right)$

Phosphate $\left(\mathrm{PO}_{4}{ }^{3-}\right)$ was measured by the ascorbic acid method (Strickland and Parsons 1972). In this method, 
ammonium molybdate, sulfuric acid, ascorbic acid, and potassium antimonyl-tartrate was poured to water samples, which reacted with reactive phosphorous and thus formed a blue solution. Wavelength was measured at $880 \mathrm{~nm}$ with a spectrophotometer (HITACHI, Model no. U-1900, Japan).

\section{Ammonia-N $\left(\mathrm{NH}_{4}^{+}\right)$}

The concentration of ammonia- $\mathrm{N}\left(\mathrm{NH}_{4}{ }^{+}\right)$was determined through the ammonia low-level indophenol method (APHA 1991). In this method, water samples were treated with an alkaline medium, phenol, and sodium nitroprusside to form blue indophenols, which was measured at $640 \mathrm{~nm}$ with a spectrophotometer (HITACHI, Model no. U-1900, Japan).

\section{Biological oxygen demand (BOD)}

Biological oxygen demand (BOD) was determined by measuring the difference in oxygen concentrations in the sample before and after incubation in the dark at $20{ }^{\circ} \mathrm{C}$ for 5 days (APHA 1991).

Total suspended solids (TSS)

The total suspended solids (TSS) were determined by filtering $250 \mathrm{~g}$ of the water sample through previously weighted Whatman No. $47 \mathrm{~mm}$ glass microfiber filters. The filter papers were then dried in an oven at $105{ }^{\circ} \mathrm{C}$ for $24 \mathrm{~h}$ and weighted again. The difference in weights yielded the amount of suspended solids for that volume of water sample (APHA 1991).

\section{Chlorophyll $a$}

Chlorophyll $a$ was measured according to the method used by Strickland and Parsons (1972). The water samples were filtered through a $0.45 \mu \mathrm{m}$ filter paper (Whatman Cellulose Nitrate Membrane Filters) with a vacuum pump (Rocker, Model no. 300). Chlorophyll pigment was extracted by $90 \%$ acetone, and the filters were then kept frozen in the dark overnight. The samples were centrifuged at 4,000 rpm for $10 \mathrm{~min}$, and the absorbance of the extracted samples was recorded at $630,647,664$, and $750 \mathrm{~nm}$ by a spectrophotometer (HITACHI, Model no. U-1900, Japan).

Data treatment and multivariate statistical methods

The Kruskal-Wallis $\mathrm{H}$ test was used to determine the significant difference of the physicochemical parameters between sampling stations and months. The Mann-Whitney $U$ test was conducted to identify significant differences between surface water quality and bottom water quality.
The Kaiser-Meyer-Olkin (KMO) and Bartlett's sphericity tests were conducted to examine the suitability of the data for PCA and FA (Shrestha and Kazama 2007). KMO is a sampling adequacy measure that provides the proportion of variance that is a common variance (i.e., that might be caused by underlying factors). A high value (close to 1 ) generally indicates that PCA and FA are useful. In this study, KMO values were 0.578 and 0.577 for surface and bottom water, respectively. Bartlett's test of sphericity indicates whether the correlation matrix is an identity matrix, which indicates that variables are unrelated. The significance level (0 in this study, less than 0.05) indicates significant relationships among variables.

Cluster analysis is a multivariate technique that categorizes objects of the system into clusters or categories according to their similarities or dissimilarities. This classification aims to obtain optimal groups or clusters with similar observations or objects, but with the clusters dissimilar to one another. Of all CA methods, hierarchical agglomerative clustering is the most common, providing intuitive similarity relationships between any sample and the entire data set and usually illustrated by a dendrogram or tree diagram. In this study, hierarchical agglomerative CA was performed by the unweighted pair group method using arithmetic averages (UPGMA) method using Euclidean distance as a measure of similarity or dissimilarity (Shrestha and Kazama 2007). CA was conducted by MVSP software.

Factor analysis shows possible linear combinations of the original variables and reduces large number of variables into new uncorrelated few variables. PCA allows associations between variables and thereby reduces the dimension of the data matrix. These techniques provide information on the most meaningful parameters, which describe a whole data set affording data reduction with minimum loss of original information (Vega et al. 1998). The new groups of variables were extracted through PCA axis rotation (varimax rotation) (Alberto et al. 2001). All statistical data were treated through SPSS 18.0.

\section{Results and discussion}

Spatial variation of water quality parameters

The mean, standard deviation, and range of the surface and bottom water quality parameters at different stations of the Merbok estuary are shown in Table 1.

The spatial variations of water quality parameters with their average values and standard errors among six different sampling stations in Merbok estuarine system are presented in Figs. 2, 3, 4, 5, 6, 7. The depths of stations 1, 2, 3, 4,5 , and 6 were observed to be 3.83, 2.17, 2.21, 2.71, 3.70, and $3.50 \mathrm{~m}$, respectively. Water temperature varied from 


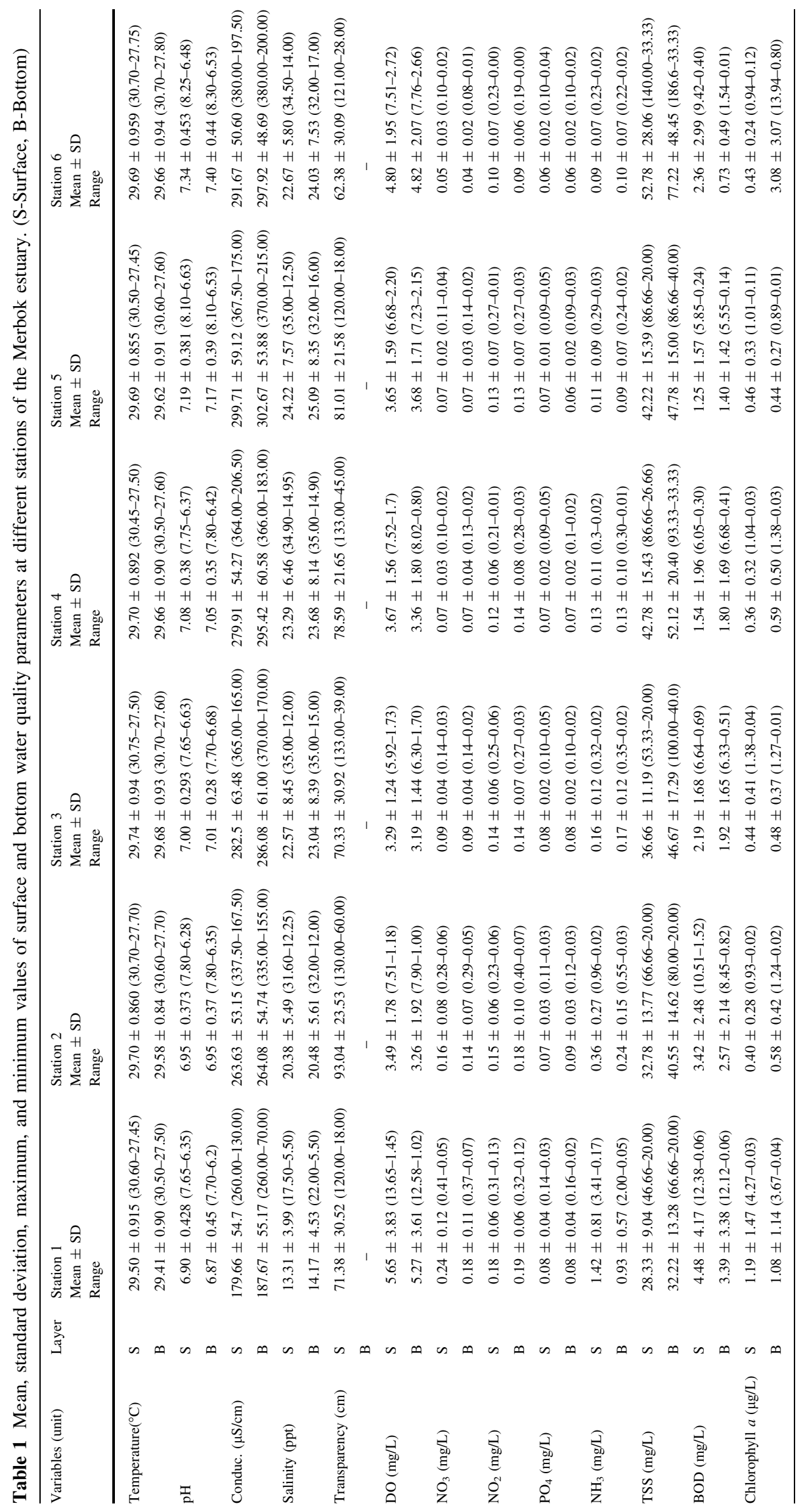



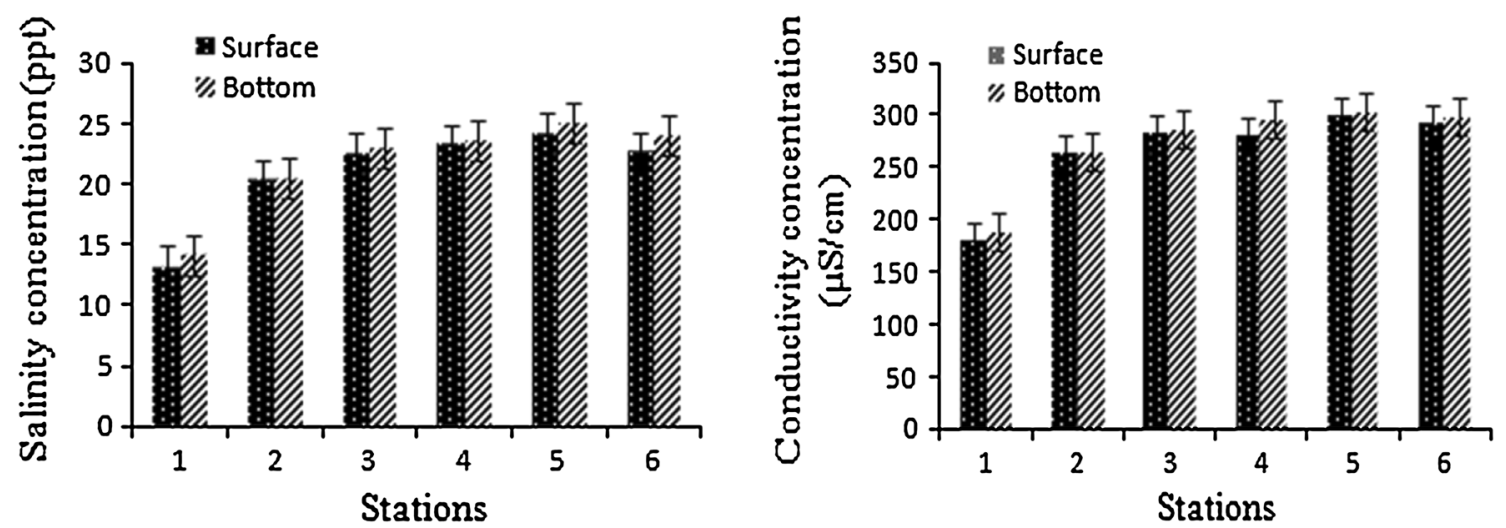

Fig. 2 The concentration of surface and bottom salinity and conductivity (Mean \pm SE) of Merbok estuary at different stations

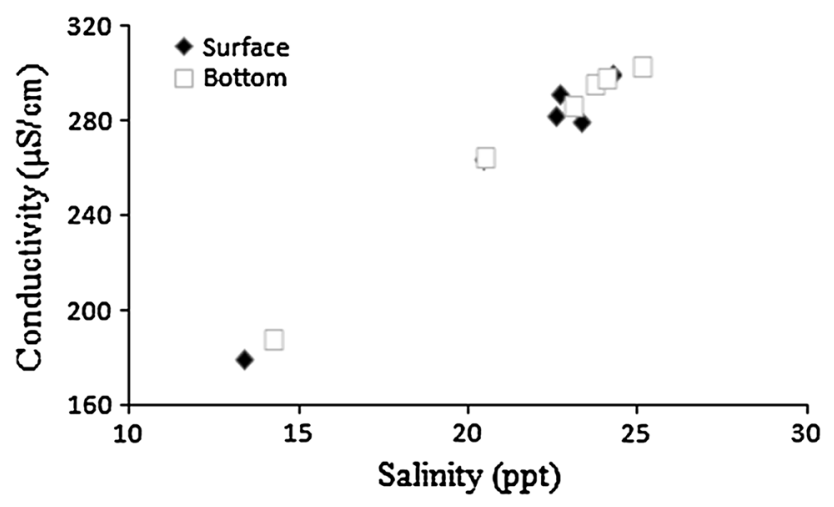

Fig. 3 The relationship between conductivity and salinity at different stations of Merbok estuary

29.50 to $29.74{ }^{\circ} \mathrm{C}$ at surface and 29.41 to $29.68{ }^{\circ} \mathrm{C}$ at the bottom. The surface water temperatures were slightly higher than the temperature of the bottom water, which may be attributed to the high-energy zone compared with the shallow and low-energy region of the estuary. Temperature was non-significant between the surface and the bottom (Mann-Whitney $U$ test, $p>0.05$ ). Temperature is the most important factor to maintain the growth, reproduction, survival, and distribution of organisms in the physical environment (Langford 1990). Because the estuary is shallow, water temperature is controlled by atmospheric temperature. Temperature controls behavioral characteristics of organisms, solubility of gases and salts in water (Vincy et al. 2012). Mean surface temperature was at its maximum at station 3 (midstream) and at its minimum at station 1 (upstream). The $\mathrm{pH}$ of the bottom water was slightly higher $(6.87-7.40)$ than that of the surface water (6.90-7.34). The $\mathrm{pH}$ was non-significant between the surface and the bottom (Mann-Whitney $U$ test, $p>0.05$ ) but significant between sampling months and stations (Kruskal-Wallis $H$ test, $p<0.001$ ). A high value at the bottom can be attributed to the vertical stratification of the water column with regard to salinity and DO. Shuhaimi-Othman

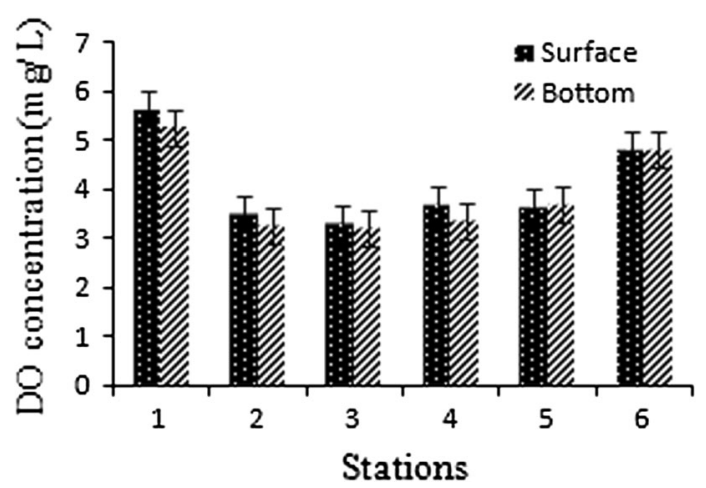

Fig. 4 The concentration of surface and bottom DO (Mean \pm SE) of Merbok estuary at different sampling stations

et al. (2007) observed that $\mathrm{pH}$ varied from 5.72 to 7.38 . The spatial variation of $\mathrm{pH}$ was recorded in this study higher downstream than upstream. Earlier studies on Indian estuaries (Upadhyay 1988; Murugan and Ayyakkannu 1991) found that $\mathrm{pH}$ varied from the surface to the bottom and that $\mathrm{pH}$ is high toward the downstream.

Salinity was ranged from 13.31 to $24.22 \mathrm{ppt}$ in the surface water and 14.17 to $25.09 \mathrm{ppt}$ in the bottom water. The surface and bottom salinities are presented in Fig. 2. In surface and bottom water, the salinity of stations 1 and 2 (upstream) was lower than that of the other stations downstream because of fresh water discharge in the upstream and density stratification. The Mann-Whitney $U$ test showed that salinity was non-significant $(p>0.05)$ between surface and bottom but significant between station and month (Kruskal-Wallis $H$ test, $p<0.001)$. Sujatha et al. (2009) also reported that surface salinity is lower than bottom salinity in most stations, indicating the prevalence of density stratification within the estuary. The influx of highly saline water and the low discharge of freshwater by rivers increased salinity in the estuary. In addition, the differences between surface and bottom salinity can be attributed to the outflowing riverine water, which creates a two-layer structure in the estuary 

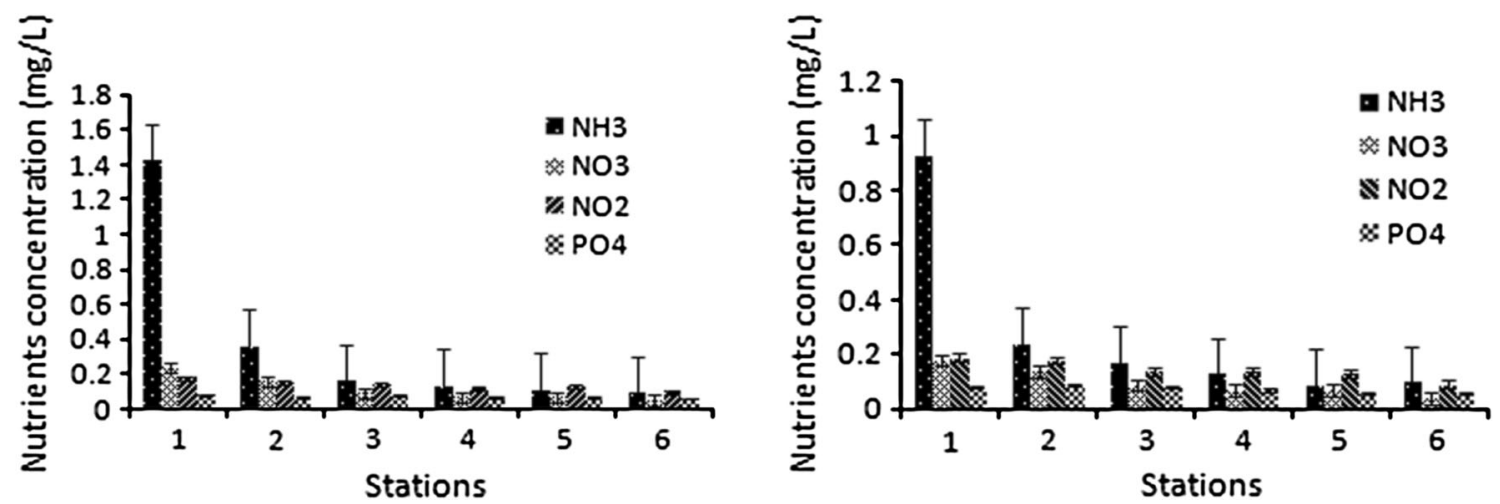

Fig. 5 The concentration of surface and bottom nutrients (Mean \pm SE) of Merbok estuary at different sampling station

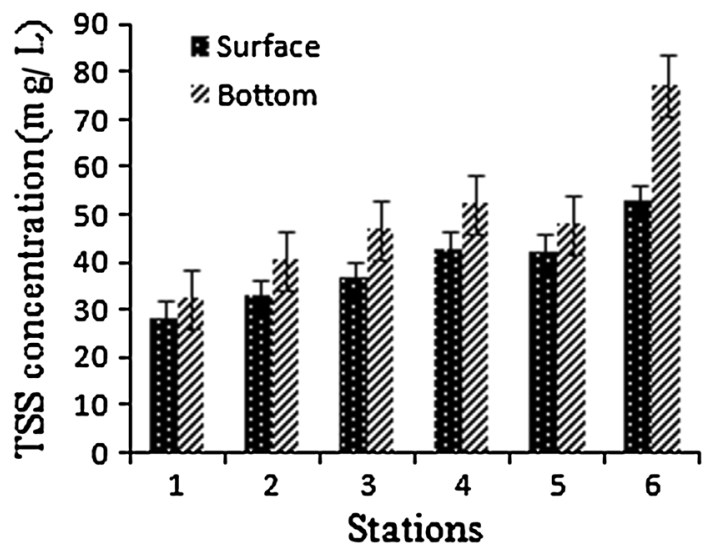

Fig. 6 The concentration of surface and bottom TSS (Mean \pm SE) of Merbok estuary at different sampling stations

(Nasnolkar et al. 1996). Moreover, increased salinity indicates increased halide ions $\left(\mathrm{Cl}^{-}, \mathrm{Fl}^{-}, \mathrm{Br}^{-}, \mathrm{I}^{-}\right)$in downstream, which may be due to increase in positive ions at downstream. Meera and Nandan (2010) found that most water-soluble salts in an aquatic environment remain in chloride form, which indicates the total amount of soluble salts in the ecosystem. Water conductivity as a function of salinity at different stations is shown in Fig. 3. A linear relationship between conductivity and salinity was observed with a coefficient ( $\Delta$ Conductivity/ $\Delta$ Salinity) of 10.88 and $10.82 \mu \mathrm{S} / \mathrm{cm} / \mathrm{ppt}$ for the surface and bottom waters, respectively, with linear regression $r^{2}$ value of 0.97 . Therefore, water conductivity was a consequence of salinity intrusion from the downstream to upstream in the Merbok.

Surface and bottom DO are shown in Fig. 4. The DO of surface water was 3.29 to $5.65 \mathrm{mg} / \mathrm{l}$, slightly higher than that of bottom water at 3.19 to $5.27 \mathrm{mg} / \mathrm{l}$. This difference may be attributed to the high photosynthetic activity at the euphotic zone, to atmospheric input, and to high oxygen solubility in the low-salinity surface water. A comparison of surface and bottom values revealed that a vertical gradient was prominent at all stations during the study period. Satpathy et al. (2010) observed similar pattern of results. The Mann-Whitney $U$ test showed that DO was non-significant between the surface and the bottom $(p>0.05)$ but significant between months and stations (Kruskal-Wallis $H$ test, $p<0.001$ ). The highest DO value at station 1 may be due to phytoplankton photosynthesis, which acts as a major factor, and to the high solubility of oxygen in low surface water. The lowest value of oxygen found in station 3 (middle stream) may be due to organic waste water discharge, which increased organic matter; this organic matter subsequently decomposed and reduced DO in this station. Anila Kumary et al. (2007) found that oxygen level is maintained to a limit by the high photosynthetic activity and periodic flushing characteristics of the estuary. The same study observed that local production, diffusion and advection, exchange of oxygen across the surface, and biochemical utilization are controlling factors for DO in many aquatic environments.

The surface and bottom concentration of nutrients are presented in Fig. 5. $\mathrm{NO}_{3}{ }^{-}, \mathrm{NO}_{2}{ }^{-}$, and $\mathrm{NH}_{4}{ }^{+}$were higher at station 1 (upstream) than at other stations (downstream), indicating the effect of anthropogenic discharge. Nutrients were more abundant on the surface than in the bottom waters at station 1 . This nutrient concentration pattern may be attributed to the point and nonpoint sources of pollution and erosion effects. Point source pollution is attributed to domestic wastewater discharged from upstream human settlements, whereas nonpoint source pollution is contributed by agricultural and livestock farms (Madramootoo et al. 1997). The $\mathrm{NO}_{3}{ }^{-}$concentration in the surface and bottom water varied from 0.05 to 0.24 and 0.04 to $0.18 \mathrm{mg} /$ $\mathrm{L}$, respectively (Table 1 ). The maximum concentration was observed upstream (station 1). Nitrate may be flushed by rainwater, excessive use of fertilizers, and wastewater drainage. Previous study also observed that high nitrate values were found in severely polluted areas of Adayar mangrove waters (Selvam et al. 1994). The concentration of $\mathrm{NO}_{2}{ }^{-}$in surface and bottom water varied from 0.10 to 0.18 and 0.09 to $0.19 \mathrm{mg} / \mathrm{L}$, respectively (Table 1 ). $\mathrm{NO}_{3}{ }^{-}$ 

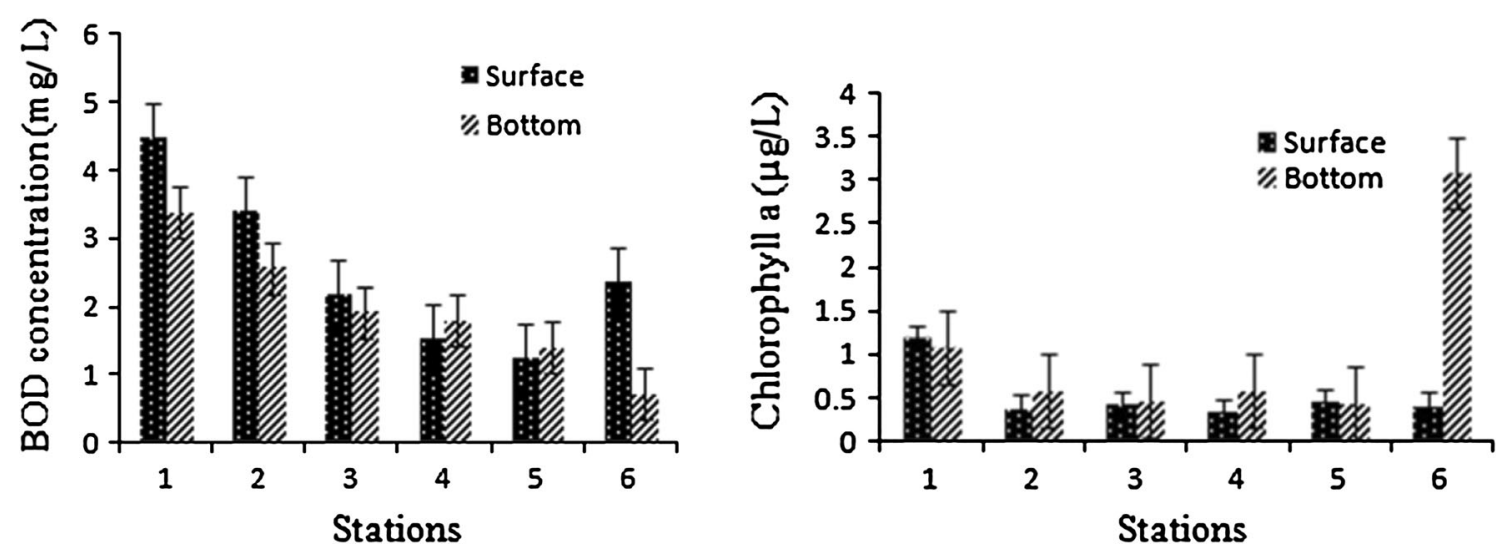

Fig. 7 The surface and bottom concentration of BOD and chlorophyll $a$ (Mean \pm SE) at different sampling stations of Merbok estuary

and $\mathrm{NO}_{2}{ }^{-}$were non-significant between the surface and the bottom (Mann-Whitney $U$ test, $p>0.05$ ) but significant between stations and months (Kruskal-Wallis $H$ test, $p<0.001)$. The oxidation of $\mathrm{NH}_{3}$ releases $\mathrm{NO}_{2}{ }^{-}$to the aquatic environment, as a result of the digenetic decomposition of estuarine sediment rich in organic matter (Correl et al. 1992). The present study also showed that nitrite value was lower in compare to nitrate value. Nandan (2004) reported that higher nitrate content concomitant with low nitrite which may be resulted from nitrification process in case of Kadinamkulam estuary.

The $\mathrm{NH}_{4}{ }^{+}$concentration in the surface and bottom water ranged from 0.09 to 1.42 and 0.09 to $0.93 \mathrm{mg} / \mathrm{L}$, respectively (Table 1). The highest amount of ammonia was recorded at station 1 (upstream) compared with other stations because of the effects of solid wastes dumped from residential areas and anthropogenic activities upstream. Previous study by Raj et al. (2013) found that higher level of ammonia was found in estuary, which may be due to the excretion and decomposition of aquatic organism in the ecosystem. Adam et al. (2001) also suggested that direct runoff from agricultural land is responsible for the highnitrogen burden of water bodies. $\mathrm{PO}_{4}{ }^{3-}$ concentration in the surface and bottom water ranged from 0.06 to 0.08 and 0.06 to $0.09 \mathrm{mg} / \mathrm{L}$, respectively. The lowest $\mathrm{PO}_{4}{ }^{3-}$ was found in the downstream compared with the upstream. This higher concentration in the upstream may be due to agricultural runoff from nearby fertilizer-treated paddy fields. Sujatha et al. (2009) found that phosphorus is increased by rainfall, land runoff, and phosphorus-rich sediment from connecting tributaries. Mann-Whitney $U$ test results showed that $\mathrm{NH}_{4}{ }^{+}$ and $\mathrm{PO}_{4}{ }^{3-}$ were non-significant between the surface and the bottom $(p>0.05)$ but significant between stations and months (Kruskal-Wallis $H$ test, $p<0.001$ ).

TSS ranged from 28.33 to $52.78 \mathrm{mg} / \mathrm{L}$ in surface water and 32.22 to $77.22 \mathrm{mg} / \mathrm{L}$ in bottom water (Fig. 6). The highest value, $77.22 \mathrm{mg} / \mathrm{L}$, was found in the bottom water of station 6 (downstream) compared with other stations because of the wastewater input and saltwater intrusion downstream. Jonnalagadda and Mhere (2001) found that TSS is increased by runoff from upstream farms and uncontrolled pollution. TSS was higher in bottom water than in surface water, indicating that TSS was modulated differently by settling or resuspension near the bottom and by advection in the surface water. Sewage discharge significantly affects the increase in the TSS concentration of the estuary (Muduli et al. 2011). Mann-Whitney $U$ test results showed that TSS was significant between the surface and the bottom $(p<0.001)$.

The highest transparency was found in station 2 (upstream), with an average of $93.04 \mathrm{~cm}$ (Table 1). The lowest value was observed in station 6 (downstream), with an average of $62.38 \mathrm{~cm}$; this minimum value may be due to runoff from the surrounding catchment, which introduces turbid waters to the study sites and to the lower reaches of the estuary as a settling basin. Another reason may be the turbid water produced by high salinity, which reduces transparency. Anitha and Kumar (2013) found that turbidity may be significantly increased by wind stirring up the bottom sediment in the estuary. Qasim (2004) indicated that the transparency of estuaries is influenced by spatial, temporal, and climatic variations together with tidal flow.

Biological oxygen demand varied from 1.25 to 4.48 and 0.73 to $3.39 \mathrm{mg} / \mathrm{L}$ for surface and bottom water, respectively (Fig. 7). Station 1 recorded high values of BOD at the surface and bottom water probably because of the influx of organic sewage from anthropogenic activities; thus, station 1 was categorized as a polluted station. In addition, surface water exhibited high BOD, which may be due to organic suspended materials from discharged wastewater. This condition may also be due to the effect of dead and decaying mangrove vegetation resulting in increased BOD in this study area. Similar results were also observed by previous studies (Grafny et al. 2000; Fianko et al. 2010). BOD was non-significant between the surface and the bottom (MannWhitney $U$ test, $p>0.05$ ) but significant between months and stations (Kruskal-Wallis $H$ test, $p<0.001$ ). 
Fig. 8 Dendrogram obtained by cluster analysis using UPGMA method and Euclidian distances for all six sampling stations according to surface and bottom water quality parameters of the Merbok estuary

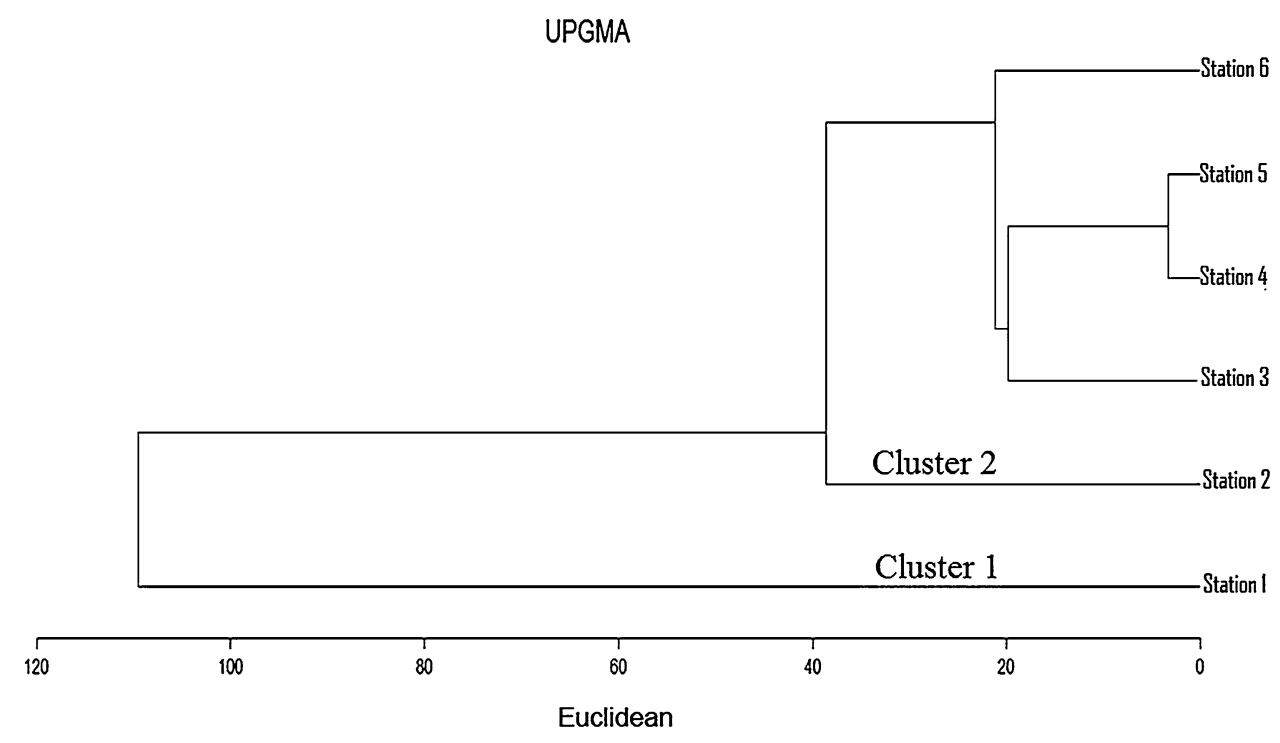

Chlorophyll $a$ concentration is an indicator of phytoplankton biomass. High concentrations of chlorophyll $a$ would result in high values of productivity and high phytoplankton biomass. Chlorophyll $a$ concentration ranged from 0.36 to 1.19 and 0.44 to $3.08 \mu \mathrm{g} / \mathrm{L}$ for surface and bottom water, respectively (Fig. 7). A marginally increasing trend of chlorophyll $a$ was noticed from the station 1 to station 6 (Table 1). The surface and bottom concentration of chlorophyll $a$ at the sampling stations showed a peculiar trend, whereas relatively high-surface chlorophyll $a$ was found at station 1 and station 5 . However, the bottom values were relatively high at stations 2, 3, 4, and 6 compared with surface concentrations. Stations 1 and 5 showed higher depth with lower chlorophyll $a$ at the bottom. On the other hand, stations 2, 3, 4, and 6 showed lower depth with higher chlorophyll $a$ at the bottom. The present research observed that station 1 showed high chlorophyll $a$, it may be due to nutrients while, station 6 showed reverse result which may be due to combined effects of light, shallow depth, and mechanical processes like turbulent mixing. Previous study by Satpathy et al. (2010) reported higher chlorophyll a concentration in bottom layer in compare to surface water. Meera and Nandan (2010) observed that higher chlorophyll a coincided with low nitrate; nitrite and phosphate concentration in Valanthakad backwater in Kerala. However, Van Duyl et al. (2002) have also opined that enhanced nutrient supply might trigger the size increase in cells, which would ultimately increase the chlorophyll $a$ concentration. Chlorophyll $a$ increased to its maximum in the upstream, decreased in the midstream, and increased again in the downstream, probably because of adequate nutrients that allow photosynthesis in the presence of light and thus enable the growth of phytoplankton. This observation is similar to that of a previous study (Damme et al. 2005; Sarupria and Bhargava 1998). Mann-Whitney $U$ test results showed that chlorophyll $a$ was significant between the surface and the bottom $(p<0.001)$ and stations and months (Kruskal-Wallis $H$ test, $p<0.001$ ).

Cluster analysis (CA)

Cluster analysis was performed on all six sampling stations against both surface and bottom water quality parameters. This analysis was used to detect the similarity or dissimilarity of groups between the sampling stations. Hierarchical CA using the UPGMA method based on Euclidean distance produced two significant clusters. Cluster diagram (Fig. 8) indicated that station 1 formed cluster 1 , the most polluted station. Stations 2-6 formed cluster 2, which showed almost similar behavior as all stations were only slightly polluted. This similar result is supported by Muduli et al. (2011).

Spatial CA rendered a dendrogram (Fig. 8), where station 1 was the most polluted $(91.31 \%)$ and had the highest dissimilarity $(87.19 \%)$ for surface and bottom water compared with other stations. Station 1 was located upstream and received pollution from nonpoint sources, mostly from anthropogenic and agricultural activities. By contrast, the lowest pollution $(2.77 \%)$ and dissimilarity $(7.15 \%)$ were found in stations 4 and 5 for surface and bottom water, respectively. These stations received pollution from point and nonpoint sources, namely, domestic wastewater and runoff from upstream.

\section{Factor analysis (FA)}

Factor analysis was conducted on the data sets (12 variables) to compare the compositional patterns between analyzed samples (water quality parameters) and to identify the sources of variation. FA yielded four factors with an eigenvalue $>1$, explaining 72.93 and $68.90 \%$ of the 
Table 2 Results of the factor analysis of surface and bottom water quality parameters for the Merbok estuary

\begin{tabular}{|c|c|c|c|c|c|}
\hline Layer & Variables & Factor 1 & Factor 2 & Factor 3 & Factor 4 \\
\hline \multirow[t]{15}{*}{ Surface } & Conductivity & $0.868^{\mathrm{a}}$ & 0.314 & & \\
\hline & $\mathrm{NO}_{3}^{-}$ & $-0.814^{\mathrm{b}}$ & & & \\
\hline & Salinity & $0.804^{\mathrm{a}}$ & & & \\
\hline & $\mathrm{NH}_{4}^{+}$ & -0.693 & & & 0.436 \\
\hline & Temperature & 0.582 & -0.330 & 0.448 & \\
\hline & TSS & & $0.776^{\mathrm{a}}$ & & \\
\hline & $\mathrm{pH}$ & & 0.712 & & \\
\hline & $\mathrm{NO}_{2}^{-}$ & -0.388 & -0.665 & & \\
\hline & BOD & -0.440 & 0.541 & -0.332 & 0.401 \\
\hline & DO & & & $0.892^{\mathrm{a}}$ & \\
\hline & Chlorophyll $a$ & & & $0.826^{\mathrm{a}}$ & \\
\hline & $\mathrm{PO}_{4}^{3-}$ & & & & $0.913^{\mathrm{a}}$ \\
\hline & Eigenvalue & 3.698 & 2.189 & 1.775 & 1.090 \\
\hline & Variance $(\%)$ & 27.46 & 18.28 & 15.43 & 11.75 \\
\hline & Cumulative (\%) & 27.46 & 45.74 & 61.17 & 72.93 \\
\hline Layer & Variables & Factor 1 & Factor 2 & Factor 3 & Factor 4 \\
\hline \multirow[t]{15}{*}{ Bottom } & Conductivity & $0.876^{\mathrm{a}}$ & & & \\
\hline & $\mathrm{NO}_{3}^{-}$ & $-0.792^{\mathrm{b}}$ & & & \\
\hline & Salinity & $0.754^{\mathrm{a}}$ & & & \\
\hline & $\mathrm{NH}_{4}^{+}$ & -0.734 & & 0.313 & \\
\hline & $\mathrm{NO}_{2}^{-}$ & -0.658 & & -0.414 & \\
\hline & Chlorophyll $a$ & & $0.773^{\mathrm{a}}$ & & \\
\hline & DO & & $0.754^{\mathrm{a}}$ & & \\
\hline & $\mathrm{PO}_{4}{ }^{3-}$ & & 0.730 & & \\
\hline & BOD & & 0.323 & $0.773^{\mathrm{a}}$ & \\
\hline & Temperature & & 0.463 & -0.671 & \\
\hline & $\mathrm{pH}$ & & & 0.551 & \\
\hline & TSS & & & & $0.948^{\mathrm{a}}$ \\
\hline & Eigenvalue & 3.497 & 2.155 & 1.607 & 1.009 \\
\hline & Variance $(\%)$ & 27.63 & 18.11 & 14.46 & 8.70 \\
\hline & Cumulative (\%) & 27.63 & 45.74 & 60.20 & 68.90 \\
\hline
\end{tabular}

Extraction method: Principal Component Analysis. Rotation method: Varimax with Kaiser Normalization

a Parameters with strong positive factors loading

b Parameters with strong negative factors loading

total variance for surface and bottom water, respectively. An eigenvalue measures the significance of factors. The factors with the highest eigenvalues are the most significant and responsible for explaining large variation in data. The eigenvalues, percentages, and cumulative percentage variances of the four identified factors are presented in Table 2 . FA was performed on the correlation matrix between different parameters according to varimax rotation. Liu et al. (2003) classified factor loading as "strong", "moderate", and "weak", corresponding to absolute loading values of $>0.75,0.75-0.50$, and $0.50-0.30$, respectively.
The parameter loadings for the four factors from the FA data (Table 2) illustrate that most of the variables associated with one another were well defined and contributed slightly to other factors, facilitating the interpretation of the results. The four factors may be attributed to the three substantial sources of anthropogenic activities.

Factor 1 of the surface water accounted for $27.46 \%$ of the total variance, which had strong positive loading for conductivity and salinity, strong negative loading for $\mathrm{NO}_{3}{ }^{-}$, moderate negative loading for $\mathrm{NH}_{4}{ }^{+}$, moderate positive loading for temperature, and week negative loading for $\mathrm{NO}_{2}{ }^{-}$and BOD. However, in the case of the bottom water, factor 1 contributed $27.63 \%$ of the total variance, which had strong positive loading for conductivity and salinity, strong negative loading for $\mathrm{NO}_{3}{ }^{-}$, and moderate negative loading for $\mathrm{NO}_{2}{ }^{-}$and $\mathrm{NH}_{4}{ }^{+}$. Factor 1 of the surface and bottom water had strong loading for salinity and conductivity, indicating that seawater significantly influenced the water chemistry of the estuary, and both parameters were influenced by the salt contents of seawater. Factor 1 of both surface and bottom water inorganic nutrients showed almost similar patterns, which may be due to the shallow depth of the estuary. The second factor in the surface water accounted for $18.28 \%$ of the total variance and had strong positive loading for TSS, moderate positive loading for $\mathrm{pH}$ and BOD, and moderate negative loading for $\mathrm{NO}_{2}{ }^{-}$. This factor can be called the soil erosion effect. However, in the case of bottom water, this factor contributed $18.11 \%$ of the total variance, strong positive loading for chlorophyll $a$ and DO, and had moderate positive loading for $\mathrm{PO}_{4}{ }^{3-}$. The third factor of surface and bottom explained 15.43 and $14.46 \%$ of the total variance and had strong positive loading for DO and chlorophyll $a$. This factor is responsible for autotrophic aquatic environment. By contrast, the third factor of bottom water had strong positive loading for BOD, moderate positive loading for $\mathrm{pH}$, and moderate negative loading for temperature. This factor can be called organic nutrients, which represent pollution from domestic waste and nutrients. BOD is the amount of oxygen required by aerobic microorganisms to oxidize organic matter to a stable inorganic form. The fourth factor of surface accounted for $11.75 \%$ of total variance which had strong positive loading for $\mathrm{PO}_{4}{ }^{3-}$. This factor can be called inorganic nutrients and represents pollution from domestic waste and agricultural sewage. High concentration of phosphates indicates the presence of pollutants that are largely responsible for anthropogenic activities and organic decomposition of leaves. The fourth factor of bottom water accounted for $8.7 \%$ of total variance, which had strong positive loading for TSS. The data in Table 2 also reveal that conductivity, salinity, DO, chlorophyll $a$, and $\mathrm{NO}_{3}{ }^{-}$were the most influential parameters contributing to water quality fluctuations in the Merbok estuary for the surface and the bottom. Vega et al. (1998) assessed the 
seasonal and polluting effects on water quality of the Pisuerga River in Spain through exploratory data analysis. The first factor in this study was mostly contributed by water quality parameters related to mineral and inorganic nutrient. Alkarkhi et al. (2009) investigated the surface water quality of selected estuaries of Malaysia through principal factor analysis. However, the second and third factors in this study were mostly contributed by domestic sewage pollution and surface runoff and other agriculture activities. The results for surface and bottom water in the current research are supported by Alkarkhi et al. (2009) and Vega et al. (1998).

\section{Conclusion}

Water quality parameters analyzed through CA, PCA, and FA revealed that nutrients, such as $\mathrm{NO}_{3}{ }^{-}, \mathrm{NO}_{2}{ }^{-}, \mathrm{NH}_{4}{ }^{+}$, $\mathrm{PO}_{4}{ }^{3-}$, and $\mathrm{BOD}$, were higher in upstream (station 1) than downstream, indicating that nutrient concentration in the estuary is regulated by freshwater flow from upstream and by tidal mixing. In addition, this condition may be due to anthropogenic activities and surface runoff. By contrast, TSS and salinity were higher in downstream (station 6) in both surface and bottom water than upstream (station 1) possibly because of erosion effects and increased positive ions. Station 1 was the most polluted station because of anthropogenic activities. These results were also supported by CA. Results from PCA showed that conductivity, salinity, $\mathrm{DO}$, chlorophyll $a$, and $\mathrm{NO}_{3}{ }^{-}$were the most significant parameters contributing to surface and bottom water quality fluctuations in the Merbok estuary. This study provides better understanding of the ecological conditions of the tropical estuary and may thus help management authorities in planning strategies for integrated estuarine managementrelated issues to maintain a sustainable ecosystem. In addition, this study allows scientists to better understand and visualize critical processes in the estuarine system.

Acknowledgments The study was funded through USM Grant Number 1001/PBIOLOGI/844083, Research University Grant 1001/PBIOLOGI/815048 and 1001/PBIOLOGI/815053. The author acknowledges USM (Universiti Sains Malaysia) for providing all research facilities, TWOWS (Third World Organization for Women in Science) and Sida (Swedish International Development Cooperation Agency) for supporting this study.

\section{References}

Adam S, Pawert M, Lehmann R, Roth B, Müller E, Triebskorn R (2001) Physicochemical and morphological characterization of two small polluted streams in southwest Germany. J Aquat Ecosyst Stress Recover 8(3-4):179-194

Adams VD (1991) Water and wastewater examination manual. Lewis, Michigan
Aiken RS, Leigh CH, Leinbach TR, Moss MR (1982) Development and environment in peninsular Malaysia. McGraw-Hill International Book Company, Singapore

Alberto WD, Fabiana PS, Cecilia HA (2001) Pattern recognition techniques for the evaluation of spatial and temporal variations in water quality. A case study: Suquia a River Basin (CórdobaArgentina). Water Res 35(12):2881-2894

Alkarkhi AFM, Ahmad A, Easa AM (2009) Assessment of surface water quality of selected estuaries of Malaysia: multivariate statistical techniques. Environmentalist 29(3):255-262

Anila Kumary KS, Azis PA, Natarajan P (2007) Water quality of the Adimalathura Estuary, southwest coast of India. J Mar Biol Assoc India 49(1):01-06

Anitha G, Kumar SP (2013) Seasonal variations in physico-chemical parameters of Thengapattanam estuary, South west coastal zone, Tamilnadu, India. Int J Environ Sci 3(4):1253-1261

ANZECC/ARMCANZ (2000) Australian and New Zealand guidelines for fresh and marine water quality, Volume 1. The guidelines (Chapters 1-7). Canberra, Australian and New Zealand Environment and Conservation Council and Agriculture and Resource Management Council of Australia and New Zealand

APHA (1991) Standard methods for the examination of water and waste water. American Public Health Association (18th Ed.), Washington, DC, USA

Boyer JN, Kelble CR, Ortner PB, Rudnick DT (2009) Phytoplankton bloom status: chlorophyll $a$ biomass as an indicator of water quality condition in the southern estuaries of Florida, USA. Eco Indic 9(6):56-67

Bu H, Tan X, Li S, Zhang Q (2010) Water quality assessment of the Jinshui River (China) using multivariate statistical techniques. Environ Earth Sci 60(8):1631-1639

Correl DL, Jordan TE, Weller DE (1992) Nutrients flux in a landscape: effects of coastal land use and terrestrial community mosaic on nutrient transport to coastal waters. Estuaries 15:431-442

Damme SV, Struyf E, Maris T, Ysebaert T, Dehairs F, Tackx M, Meire P (2005) Spatial and temporal patterns of water quality along the estuarine salinity gradient of the Scheldt estuary (Belgium and The Netherlands): results of an integrated monitoring approach. Hydrobiology 540(1):29-45

DDI PM (1974) Hydrological data: stream flow records, 1965-70. Ministry of Agricultural and Rural Development, Malaysia

DID (2001) Annual report. Department of Irrigation and Drainage, Kuala Lumpur

DOE (1999) Environmental quality report. Ministry of Science, Technology and Environment, Kuala Lumpur

Fianko JR, Lowor ST, Donkor A, Yeboah PO (2010) Nutrient chemistry of the Densu River in Ghana. Environmentalist 30(2):145-152

Grafny S, Goren M, Gasith A (2000) Habitat condition and fish assemblage structure in a coastal Mediterranean stream (Yarqon, Israel) receiving domestic effluent. Hydrobiology 422:319-330

Hu J, Qiao Y, Zhou L, Li S (2012) Spatiotemporal distributions of nutrients in the downstream from Gezhouba Dam in Yangtze River, China. Environ Sci Pollut Res 19(7):2849-2859

Huang J, Ho M, Du P (2011) Assessment of temporal and spatial variation of coastal water quality and source identification along Macau peninsula. Stoch Environ Res Risk Assess 25(3):353-361

Huot Y, Babin M, Bruyant F, Grob C, Twardowski MS, Claustre H (2007) Does chlorophyll a provide the best index of phytoplankton biomass for primary productivity studies? Biogeosci Discuss 4(2):707-745

Iscen CF, Emiroglu Ö, Ilhan S, Arslan N, Yilmaz V, Ahiska S (2008) Application of multivariate statistical techniques in the assessment of surface water quality in Uluabat Lake, Turkey. Environ Monit Assess 144:269-276

Jonnalagadda S, Mhere G (2001) Water quality of the Odzi River in the eastern highlands of Zimbabwe. Water Res 35(10):2371-2376 
Juahir H, Zain SM, Yusoff MK, Hanidza TIT, Armi ASM, Toriman ME, Mokhtar M (2011) Spatial water quality assessment of Langat River Basin (Malaysia) using environmetric techniques. Environ Monit Assess 173(1):625-641

Kjerfve B (1979) Measurement and analysis of water current, temperature, salinity and density. Estua. Hydro. Sediment. Cambridge: $186-216$

Langford TEL (1990) Ecological effects of thermal discharges. Elsevier Applied Science Publication Ltd, England

Liu CW, Lin KH, Kuo YM (2003) Application of factor analysis in the assessment of ground water in a blackfoot disease area in Taiwan. Sci Total Environ 313:77-89

Madramootoo CA, Johnston WR, Willardson LS (1997) Management of agricultural drainage water quality (Vol. 13), International Commission

Meera S, Nandan SB (2010) Water quality status and primary productivity of Valanthakad Backwater in Kerala. Indian J Mar Sci 39(1):105-113

Muduli PR, Vinithkumar N, Begum M, Robin R, Vardhan KV, Venkatesan R, Kirubagaran R (2011) Spatial variation of hydrochemical characteristics in and around port Blair Bay Andaman and Nicobar Islands, India. World Appl Sci J 13(3):564-571

Murugan A, Ayyakkannu K (1991) Ecology of uppanar backwaters, Cuddalore: 1. physico-chemical parameters. Mahasagar 24(1):31-38

Mustapha A, Abdu A (2012) Application of principal component analysis and multiple regression models in surface water quality assessment. J Environ Earth Sci 2(2):16-23

Mustapha A, Aris AZ (2012) Spatial aspects of surface water quality in the Jakara Basin, Nigeria using chemometric analysis. J Environ Sci Health Part A 47(10):1455-1465

Mustapha A, Aris AZ, Juahir H, Ramli MF, Kura NU (2013) River water quality assessment using environmentric techniques: case study of Jakara River Basin. Environ Sci Pollut Res, 1-15

Nandan BS (2004) Ecology of retting zones. In: Impact of retting on the aquatic ecosystems (Limnological Association of Kerala ISBN: 81-901939-0-2) pp 15

Nasnolkar CM, Shirodhkar PV, Singbal SVS (1996) Studies of organic carbon, nitrogen and phosphorus in the sediments of Mandovi estuary, Goa. Indian J Mar Sci 25:120-124

Nichol SL, Howard FJF, Kool J, Stowar M, Bouchet P, Radke L, Siwabessy J, Przeslawski R, Picard K, de Glasby BA, Colquhoun J, Letessier T, Heyward A (2013) Oceanic shoals Commonwealth Marine Reserve (Timor Sea) biodiversity survey GA0339/SOL5650 - post-survey report. National Environmental Research Program. Available: www.ga.gov.au

Ong J, Gong W, Wong C, Din ZH, Kjerfve B (1991) Characterization of a Malaysian mangrove estuary. Estuar Coasts 14(1):38-48

Pejman AH, Nabi Bidhendi GR, Karbassi AR, Mehradi N, Esmaeili Bidhendi M (2009) Evaluation of spatial and seasonal variations in surface water quality using multivariate statistical techniques. Int J Environ Sci Tech 6(3):467-476

Pradhan U, Shirodkar P, Sahu B (2009) Physico-chemical characteristics of the coastal water off Devi estuary, Orissa and evaluation of its seasonal changes using chemometric techniques. Curr Sci 96(9):1203-1209

Qadir A, Malik RN, Husain SZ (2008) Spatio-temporal variations in water quality of Nullah Aik-tributary of the river Chenab, Pakistan. Environ Monit Assess 140(1):43-59

Qasim SZ (2004) Environmental features and biological characteristics. Handbook of tropical estuarine biology. Narendra Publishing House, Delhi, pp 1-72

Raj MV, Padmavathy S, Sivakumar S (2013) Water quality parameters and it influences in the Ennore estuary and near Coastal environment with respect to industrial and domestic sewage. Int Res J Environ Sci 2(7):20-25
Rosnani I (2000) River water quality status in Malaysia. In Proceedings national conference on sustainable river basin management in Malaysia. Kuala Lumpur, Malaysia

Rossouw N (2003) Chlorophyll a as indicator of algal abundance. http://www.ru.ac.za/static/institutes/iwr/software/reserve/wqdss/ Algal_Abundance_V01.htm. Accessed 11 March 2014

Sarupria J, Bhargava R (1998) Seasonal distribution of chlorophyll-a in the exclusive economic zone (EEZ) of India. Indian J Mar Sci 27:292-297

Satpathy K, Mohanty A, Natesan U, Prasad M, Sarkar S (2010) Seasonal variation in physicochemical properties of coastal waters of Kalpakkam, east coast of India with special emphasis on nutrients. Environ Monit Assess 164:153-171

Selvam V, Hariprasad RMA, Ramasubramanian R (1994) Diurnal variations in the water quality of sewage polluted Adayar mangrove water, east coast of India. Ibid 23:94-97

Shrestha S, Kazama F (2007) Assessment of surface water quality using multivariate statistical techniques: a case study of the Fuji river basin, Japan. Environ Model Softw 22(4):64-475

Shuhaimi-Othman M, Lim EC, Mushrifah I (2007) Water quality changes in Chini Lake, Pahang, West Malaysia. Environ Monit Assess 131(1):279-292

Singh KP, Malik A, Sinha S (2005) Water quality assessment and apportionment of pollution sources of Gomti River (India) using multivariate statistical techniques: a case study. Anal Chim Acta 35:3581-3592

Strickland J, Parsons (1972) A practical handbook of seawater analysis. Fish Res Bd Can Bull 167:310

Sujatha CH, Niffy B, Ranjitha R, Fanimol CL, Samantha NK (2009) Nutrient dynamics in two lakes of Kerela, India. Indian J Mar Sci 38(4):451-456

Upadhyay S (1988) Physico-chemical characteristics of the Mahanadi estuarine ecosystem, east coast of India. Indian J Mar Sci, New Delhi 17(1):19-23

US Environmental Protection Agency (2002) Integrated water quality monitoring and assessment report. Available: www.epa.gov/.../ 2002wq. Accessed 8 March 2014

Van Duyl FC, Gast G, Steinhoff W, Kloff S, Veldhuis M, Bak R (2002) Factors influencing the short-term variation in phytoplankton composition and biomass in coral reef waters. Coral Reefs 21:293-306

Varol M, Sen B (2009) Assessment of surface water quality using multivariate statistical techniques: a case study of Behrimaz Stream, Turkey. Environ Monit Assess 159(1):543-553

Varol M, Gökot B, Bekleyen A, Şen B (2012) Spatial and temporal variations in surface water quality of the dam reservoirs in the Tigris River basin, Turkey. Catena 92:11-21

Vega M, Pardo R, Barrado E, Debán L (1998) Assessment of seasonal and polluting effects on the quality of river water by exploratory data analysis. Water Res 32(12):3581-3592

Vincy MV, Rajan B, Pradeep Kumar AP (2012) Water quality assessment of a tropical wetland ecosystem with special reference to Backwater Tourism, Kerala, South India. Int Res J Environ Sci 1(5):62-68

Wang Y, Wang P, Bai Y, Tian Z, Li J, Shao X, Li BL (2012) Assessment of surface water quality via multivariate statistical techniques: a case study of the Songhua river-Harbin region, China. J Hydro-environ Res 7(1):30-40

Wetzel RG, Likens GE (2000) Limnological analyses. Springer, Berlin

Yang L, Song X, Zhang Y, Yuan R, Ma Y, Han D, Bu H (2012) A hydrochemical framework and water quality assessment of river water in the upper reaches of the Huai River Basin, China. Environ Earth Sci 67(7):2141-2153

Zhang X, Wang Q, Liu Y, Wu J, Yu M (2011) Application of multivariate statistical techniques in the assessment of water quality in the Southwest New Territories and Kowloon, Hong Kong. Environ Monit Assess 173(1-4):17-27 